\title{
Correction to: Feasibility of automated fetal fractional shortening measurement with two-dimensional tracking and construction of a reference range for normal fetuses
}

\author{
Sumito Nagasaki ${ }^{1,2} \cdot$ Masahiko Nakata $^{1,2} \cdot$ Mayumi Takano $^{1,2} \cdot$ Kento Usui $^{2} \cdot$ Junya Sakuma $^{1,2} \cdot$ Eijiro Hayata $^{2}$. \\ Mineto Morita ${ }^{1,2}$
}

Published online: 19 June 2019

(c) The Japan Society of Ultrasonics in Medicine 2019

\section{Correction to: Journal of Medical Ultrasonics https://doi.org/10.1007/s10396-019-00942-6}

In the original publication of the article, the Conflict of interest statement, name of institution and ID number of the ethical committee were published incorrectly. The correct details are given in this Correction.

The conflict of interest statement should read as "All declare that they there is no conflict of interest".
Under the section, "Materials and methods' first paragraph, the sentence that reads as "This study...... all participants" should read as "This study was approved by the Ethics Committee of Faculty of Medicine, Toho University (ID number A18013_A16047), and written informed consent was obtained from all participants".

Publisher's Note Springer Nature remains neutral with regard to jurisdictional claims in published maps and institutional affiliations.

The original article can be found online at https://doi.org/10.1007/ s10396-019-00942-6.

Masahiko Nakata

masahiko.nakata@med.toho-u.ac.jp

1 Department of Obstetrics and Gynecology, Toho University Graduate School of Medicine, 5-21-16 Omori-nishi, Ota City, Tokyo 143-8541, Japan

2 Department of Obstetrics and Gynecology, Toho University Omori Medical Center, Tokyo, Japan 